\title{
Modeling Energy and Development: An Evaluation of Models and Concepts
}

\author{
BAS VAN RUIJVEN \\ Utrecht University, The Netherlands
}

FRAUKE URBAN, RENÉ M.J. BENDERS, HENRI C. MOLL University of Groningen, The Netherlands

JEROEN P. VAN DER SLUIJS

Utrecht University, The Netherlands

BERT DE VRIES

Utrecht University, The Netherlands

PBL—Netherlands Environment Assessment Agency, Bilthoven, The Netherlands

and

\author{
DETLEF P. VAN VUUREN * \\ PBL—Netherlands Environment Assessment Agency, Bilthoven, The Netherlands
}

\begin{abstract}
Summary. - Most global energy models are developed by institutes from developed countries, focusing primarily on issues that are important in industrialized countries. Evaluation of the results for Asia of the IPCC/SRES models shows that broad concepts of energy and development, the energy ladder and the environmental Kuznets curve, can be observed in the results of the models. However, improvements can be made in modeling the issues that underlie these concepts, like traditional fuels, electrification, economic structural change, income distribution, and informal economies. Given the rapidly growing importance of energy trajectories of developing countries for global sustainability, the challenge for the future is to develop energy models that include all these aspects of energy and development.

(C) 2008 Elsevier Ltd. All rights reserved.
\end{abstract}

Key words - developing countries, Asia, energy modeling, IPCC/SRES models

\section{INTRODUCTION}

The consumption and production of energy worldwide plays a major role in several sustainability problems, such as climate change and depletion of resources. So far, world energy use has been dominated by energy consumption in industrialized countries. However, that situation is currently changing. Industrialization, improvement of living standards and population growth are leading to rapidly increasing energy consumption in developing countries, with subsequent impacts on global sustainability issues.

Global energy models are used to explore and understand possible future changes in the global energy system. Only very few global

\footnotetext{
* The authors would like to thank Ton Schoot-Uiterkamp and Annemarije Kooijman for their comments on draft versions of this article. We are grateful to three anonymous reviewers for their useful comments on this article. Final revision accepted: January 28, 2008.
} 
energy models account explicitly for the specific dynamics of developing countries. As the majority is developed in industrialized countries, they mainly focus on issues which are important for industrialized energy systems, systems that can be characterized by full access to modern energy forms, high (and increasing) welfare levels and a minor role of agriculture in the structure of the economy. Implicitly, it is assumed that the future of developing countries can be derived from experiences in developed countries during the last decades. For a variety of reasons, this is not necessarily the case, as developed and developing countries differ for instance in market development, institutional arrangements and the existence of traditional economies and energy systems (Pandey, 2002; Shukla, 1995).

In 2000, the IPCC published a set of scenarios in the Special Report on Emission Scenarios (SRES) (IPCC, 2000a). These scenarios have been developed using global energy models, to explore future pathways for greenhouse gas (GHG) emissions. Despite the fact that developing countries play an important role in the increase in global energy consumption projected in these scenarios, all modeling teams in the SRES were from the developed world (the number of global energy modeling teams in developing countries is very limited). It should be noted that in the SRES some attempts were made to compensate for this: one modeling team involved modelers from developing countries, while the report as a whole involved several experts from developing countries as non-modeling experts. However, these activities did not change the models that were applied.

This article looks at the question whether current global energy models include several key-issues of energy systems in developing countries. In our analysis, we especially focus on the Asian region. We first evaluate whether two broad concepts of energy and development, the energy ladder and the environmental Kuznets curve, can be found in the SRES model results (Section 2). Next, we identify several key-issues of energy systems in developing countries that are relevant for global energy models. Section 3 discusses these issues, focusing on the trends and stylized facts and the relevance for global energy models. Section 4 discusses the methods and gives the conclusions.

Some remarks on this study have to be made beforehand. First, we do not claim complete- ness in the key-issues; we focus on what we consider the most relevant changes in energy systems in developing countries with respect to global energy modeling, based on our own analysis and observation. Second, we focus mainly on Asia, as among all developing regions this continent has the largest population size, experiences the fastest economic growth and consequently the fastest growing contribution to energy consumption and global climate change.

Many definitions exist for the terms "developing country" and "developing region." In this article, we define developing countries as all countries within the World Bank's low income, lower-middle, and upper-middle income groups, excluding the former Soviet regions and Central-European countries (or, in other words, all countries in Latin America, Africa, the Middle East, Asia, and Oceania that are not in the high income class). We use the terms developing country and developing region interchangeably.

\section{(a) Metrics for the comparison of economic activity}

Most energy models use economic activity (GDP/capita, representing living-standards) as driving force for energy related issues. When internationally comparing economic activity, one has to express local currencies in a common currency. Two options are available for such comparison: market exchange rates (MER, usually US dollars) or purchasing power parity (PPP, expressed as international dollars). MER comparison is based on bilateral exchange rates between different currencies and the US dollar, but this ignores the often large differences in prices of a broad set of goods and services that are not reflected in the value of the exchange rate. The PPP exchange rate is defined as the ratio of prices for a representative basket of goods and services, such that the purchasing power of the currencies is equal (Lafrance \& Schembri, 2002). Usually, North American purchasing power in US dollars is set to equal international dollars. Developing countries are usually characterized by a high ratio between PPP income levels and MER-based income levels (the so-called PPP-ratio), which makes the issue especially relevant for the modeling of energy systems in these regions. In other words, developing countries' economies are larger on PPP basis than suggested on MER basis. In the SRES, economic activity was mainly ex- 
pressed in MER terms and this has been extensively debated in long-term scenario literature (Castles \& Henderson, 2003; Grübler et al., 2004; Nordhaus, 2007; van Vuuren \& Alfsen, 2006). In the dynamic context of global models, one of the crucial questions is whether PPP values should be regarded as constant or dynamically converging with increasing welfare levels (van Vuuren \& Alfsen, 2006). Although it was found that models lead to comparable results if calibrated consistently in PPP or MER (van Vuuren \& Alfsen, 2006), this aspect contributes to uncertainty in the projection for energy use in developing countries. In this article, we use MER values in the discussion of the SRES results (Section 2) and PPP values for the analysis of data (Section 3), as PPP is more suitable for the comparison of welfare levels between different developing countries. The different use of metrics in these two sections is irrelevant for the type of comparisons that are made.

\section{DEVELOPING COUNTRIES IN GLOBAL ENERGY MODELS}

One of the few consistent databases with scenario results from global energy models is the IPCC/SRES (IPCC, 2000a). Due to the differences in regional definitions and levels of detail of the models, the reporting of model results in this database is rather rough and at a high level of aggregation. For example, results are published for only four world regions (of which we focus on the region of Asia) ${ }^{1}$ and a limited set of socio-economic and energy data. Due to these limitations, it is only possible to evaluate these models on rather aggregated concepts of energy and development. Here, we focus on the energy ladder and the environmental Kuznets curve (EKC).

The six models involved in the IPCC/SRES process are AIM, ASF, IMAGE/TIMER, MARIA, MESSAGE, and MiniCAM (IPCC, 2000a). In the IPCC/SRES, a set of four scenarios was developed, defined by an axis of global versus regional orientation and economic versus environmental preferences. The A1 storyline is a case of rapid globalization and economic development, in which average income per capita converges between world regions. The A2 scenario represents a differentiated world with a focus on materialism, in which protectionism of regions is more important than global interaction and in which significant income disparities continue to exist. The B1 storyline describes a fast-changing and convergent world, aiming at environmental, social, and economic sustainability from a global perspective. Finally, the B2 world is one of increased concern for environmental and social sustainability coupled with an emphasis on regional solutions (IPCC, 2000a). Per scenario one model is the marker model, which is illustrative of a particular storyline. On several key-variables, the results of other models are harmonized with the marker model.

In this analysis, all data are derived from the IPCC/SRES website ${ }^{2}$ except for the IMAGEmodel data: these are from the IMAGE SRES implementation CD-ROM (IMAGE-team, 2001). Ideally, we would have analyzed the source-codes and technical documentation of the models with respect to specific development issues. However, documentation of many of these models is incomplete and source codes are hard to obtain. Therefore, we decided to use the results of the models and the available model documentation. By limiting our evaluation to these models, we are aware that we exclude a range of specific energy models, among them the MARKAL/TIMES family and the IEA World Energy Model (WEM), which were not involved in the IPCC/SRES process. Also, the SRES versions of the models might be outdated as models are continuously improved. For example, the IMAGE model has been considerably improved since the SRES (Bouwman, Hartman, \& Klein Goldewijk, 2006), but no changes have been made to the processes that are relevant for energy and development issues. Also for other models we presume that little has changed on the issues that we discuss in Section 3. Finally, it should be noted that data in the sections are often presented as function of per capita income, an indicator used as a proxy of development level ${ }^{3}$

\section{(a) The energy ladder in the SRES models}

It is a general historically observed pattern that once fuels become available and affordable, populations switch to fuel-stove combinations with a higher quality (Holdren \& Smith, 2000). The energy ladder is a generic concept that postulates that household energy use often shows a transition from traditional biomass fuels (wood, dung, and crop residues) through the direct use of liquid and solid fossil fuels (coal and kerosene) to modern energy forms (LPG, natural gas, and electricity) (Barnes \& Floor, 1996; Martins, 2005; Smith, Apte, 
Yuqing, Wongsekiarttirat, \& Kulkarni, 1994). Higher ranked fuels on the energy ladder generally tend to be cleaner, more efficient and easy to use, although a switch from traditional fuels to coal is not always an improvement in this sense. On the other hand, capital costs and dependence on centralized fuel cycles also tend to increase. Critiques of the energy ladder state that reality is more complex than a simple transitional theory, for instance, because the pattern is not observed as a sequence and it is driven by more factors than increasing income (Martins, 2005; Masera, Saatkamp, \& Kammen, 2000). Especially issues like household size and location (urban, rural), and the availability of wood resources are often found to influence a households' behavior with respect to the energy ladder (Brouwer \& Falcao, 2004; Hosier \& Dowd, 1987; Kituyi et al., 2001; Top, Mizoue, Kai, \& Nakao, 2004).

To compare the energy ladder hypothesis and the results of the SRES models, we used the fraction of non-commercial fuels and electricity in secondary energy use. According to the concept, energy use should move from traditional fuels toward kerosene and electricity. Figure 1 shows the fraction of non-commercial fuels in secondary energy use for the four SRES scenarios. Only three of the six SRES models report the use of non-commercial fuels (see also
Table 1). Generally, the AIM, IMAGE, and MESSAGE models project a decreasing share of non-commercial fuels, following an (exogenously determined) exponentially declining path with increasing income levels. However, large differences exist between the models. In the AIM model, non-commercial fuels are rapidly phased out at income level of 6,000-10,000 US\$/capita, while the IMAGE model still shows a share of about $10 \%$ at $12,000 \mathrm{US} \$ / \mathrm{ca}$ pita.

Figure 2 shows the fraction of electricity in secondary energy use in relation to income for the region of Asia. All IPCC/SRES models project an increasing share of electricity with increasing income. However, large differences on path and share exist between models. The MiniCAM model projects the highest share of electricity, up to $60 \%$ in the A2 scenario. On the other extreme, the MARIA model projects hardly any increase in electricity share, in none of the A1, B1, and B2 scenarios it exceeds $15 \%$. ${ }^{4}$ The results also show diversity in the rate of growth of the electricity share; especially, the ASF A2 scenario involves rapid developments.

The results for Asia of all IPCC/SRES models involve patterns that correspond typically with the energy ladder concept: decreasing shares of traditional fuels and increasing shares of electricity use. However, in reality each rung
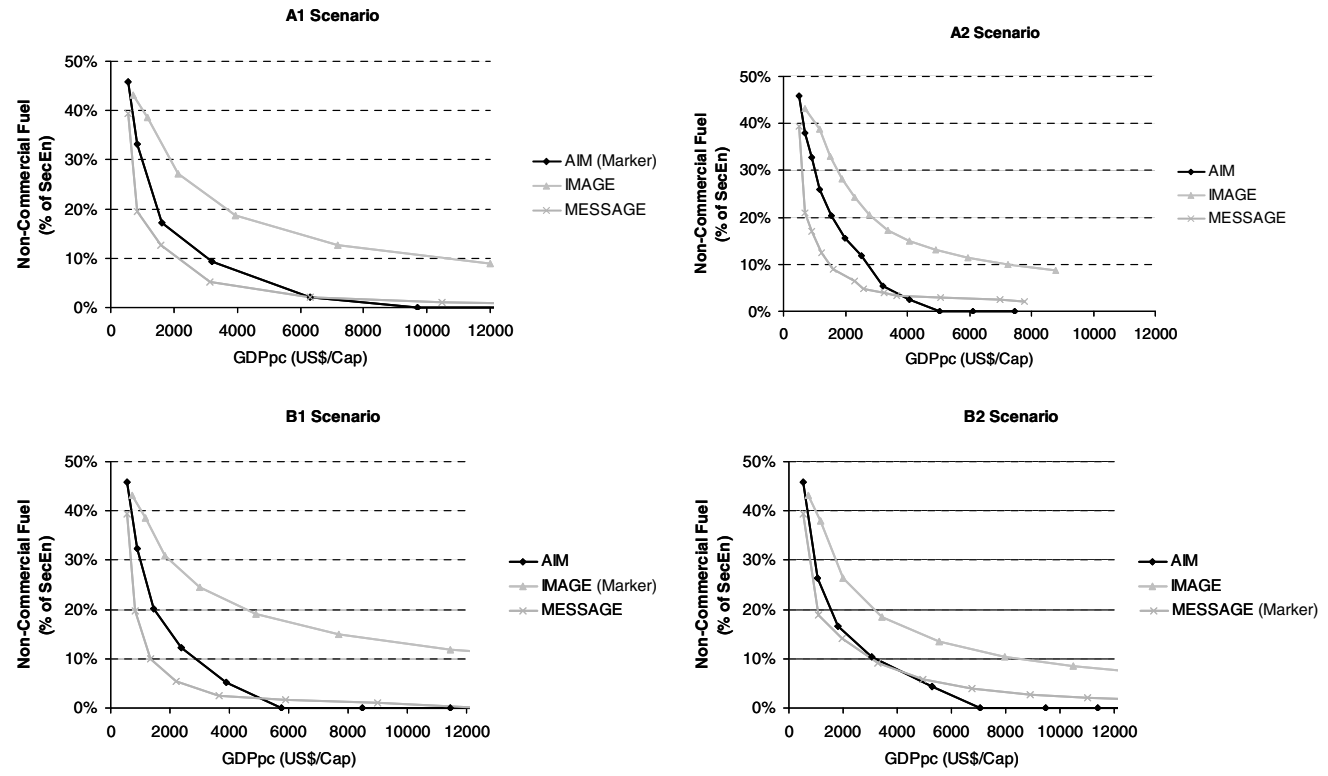

Figure 1. Fraction of non-commercial fuels in secondary energy use versus GDP/capita in MER for the region of ASIA from the SRES models. 
Table 1. Overview of issues of energy and development in the SRES models (based on IPCC, 2000a, 2000b; Mori, 2000; van der Sluijs et al., 2001)

\begin{tabular}{|c|c|c|c|c|c|c|}
\hline Model acronym & AIM & ASF & IMAGE (TIMER) & MARIA & MESSAGE & MiniCAM \\
\hline \multicolumn{7}{|l|}{ Models } \\
\hline Full name & $\begin{array}{l}\text { Asian pacific } \\
\text { integrated model }\end{array}$ & $\begin{array}{l}\text { Atmospheric } \\
\text { stabilization } \\
\text { framework }\end{array}$ & $\begin{array}{l}\text { Integrated model to } \\
\text { assess the global } \\
\text { environment }\end{array}$ & $\begin{array}{l}\text { Multi-regional } \\
\text { approach for resource } \\
\text { and industry } \\
\text { allocation }\end{array}$ & $\begin{array}{l}\text { Model for energy } \\
\text { supply strategy } \\
\text { alternatives and their } \\
\text { general } \\
\text { environmental impact }\end{array}$ & $\begin{array}{l}\text { Mini climate } \\
\text { assessment model }\end{array}$ \\
\hline Type of model & $\begin{array}{l}\text { Simulation model/ } \\
\text { dynamic }\end{array}$ & $\begin{array}{l}\text { Iterative search } \\
\text { technique } \\
\text { (optimization) }\end{array}$ & $\begin{array}{l}\text { Simulation model/ } \\
\text { dynamic, non-linear }\end{array}$ & $\begin{array}{l}\text { Optimization model/ } \\
\text { dynamic, non-linear }\end{array}$ & $\begin{array}{l}\text { Simulation, } \\
\text { optimization, } \\
\text { dynamic linear }\end{array}$ & $\begin{array}{l}\text { Economic equilibrium } \\
\text { model }\end{array}$ \\
\hline \multicolumn{7}{|l|}{ Key-issues } \\
\hline Traditional fuels & $\begin{array}{l}\text { Included, method } \\
\text { unknown }\end{array}$ & Not included & $\begin{array}{l}\text { Included, related to } \\
\text { income, urbanization } \\
\text { and oil price }\end{array}$ & Not included & $\begin{array}{l}\text { Included, method } \\
\text { unknown }\end{array}$ & Not included \\
\hline Electrification & $\begin{array}{l}\text { Implicitly included } \\
\text { via demand elasticity }\end{array}$ & $\begin{array}{l}\text { Implicitly included } \\
\text { via demand elasticity }\end{array}$ & $\begin{array}{l}\text { Implicitly included } \\
\text { via demand elasticity }\end{array}$ & $\begin{array}{l}\text { Implicitly included } \\
\text { via demand elasticity }\end{array}$ & $\begin{array}{l}\text { Implicitly included } \\
\text { via demand elasticity }\end{array}$ & $\begin{array}{l}\text { Implicitly included } \\
\text { via demand elasticity }\end{array}$ \\
\hline $\begin{array}{l}\text { Structural change, } \\
\text { (available end-use } \\
\text { sectors) }\end{array}$ & $\begin{array}{l}\text { Residential, industry, } \\
\text { commercial, } \\
\text { transport, energy } \\
\text { conversion }\end{array}$ & $\begin{array}{l}\text { Residential, industry, } \\
\text { commercial, transport } \\
\text { and electricity }\end{array}$ & $\begin{array}{l}\text { Residential, industry, } \\
\text { transport, services, } \\
\text { other }\end{array}$ & $\begin{array}{l}\text { Industry, transport, } \\
\text { public and other } \\
\text { sectors }\end{array}$ & $\begin{array}{l}\text { Industrial, residential/ } \\
\text { commercial, } \\
\text { transport, non- } \\
\text { commercial }\end{array}$ & $\begin{array}{l}\text { Residential/ } \\
\text { commercial, industry, } \\
\text { transport }\end{array}$ \\
\hline Income distribution & Not included & Not included & Not included & Not included & Not included & Not included \\
\hline Informal economy & Not included & Not included & Not included & Not included & Not included & Not included \\
\hline Resource depletion & $\begin{array}{l}\text { Based on assumed } \\
\text { exploitation cost. No } \\
\text { impact on economic } \\
\text { development }\end{array}$ & $\begin{array}{l}\text { Rogner (1997), Naki- } \\
\text { cenovic, Grubler, and } \\
\text { McDonald (1998) } \\
\text { (fossil), assumptions } \\
\text { for other resources. } \\
\text { No impact on } \\
\text { economic } \\
\text { development }\end{array}$ & $\begin{array}{l}\text { Rogner (1997) (fossil) } \\
\text { World energy } \\
\text { assessment (renew- } \\
\text { ables). No impact on } \\
\text { economic } \\
\text { development }\end{array}$ & $\begin{array}{l}\text { Rogner (1997) (fossil), } \\
\text { Fujii (1993) (renew- } \\
\text { ables), (biomass), } \\
\text { OECD/NEA (1985) } \\
\text { (uranium). Impact on } \\
\text { economic } \\
\text { development }\end{array}$ & $\begin{array}{l}\text { Rogner (1997) (fossil). } \\
\text { Consistent with } \\
\text { economic } \\
\text { development }\end{array}$ & \\
\hline $\begin{array}{l}\text { Climate change } \\
\text { (impact on economy } \\
\text { and energy system) }\end{array}$ & $\begin{array}{l}\text { No feedback on } \\
\text { economy; mitigation } \\
\text { runs possible }\end{array}$ & $\begin{array}{l}\text { No feedback on } \\
\text { economy; mitigation } \\
\text { runs possible }\end{array}$ & $\begin{array}{l}\text { No feedback on } \\
\text { economy; mitigation } \\
\text { runs possible }\end{array}$ & $\begin{array}{l}\text { Feedback on } \\
\text { economic activity; } \\
\text { mitigation runs } \\
\text { possible }\end{array}$ & $\begin{array}{l}\text { No feedback on } \\
\text { economy; mitigation } \\
\text { runs possible }\end{array}$ & $\begin{array}{l}\text { No feedback on } \\
\text { economy; mitigation } \\
\text { runs possible }\end{array}$ \\
\hline $\begin{array}{l}\text { Local air pollution } \\
\left(\mathrm{SO}_{x}\right)\end{array}$ & Yes & Yes & Yes & Not included & Yes & Yes \\
\hline
\end{tabular}

Note that we only analyzed the SRES versions of the models. 

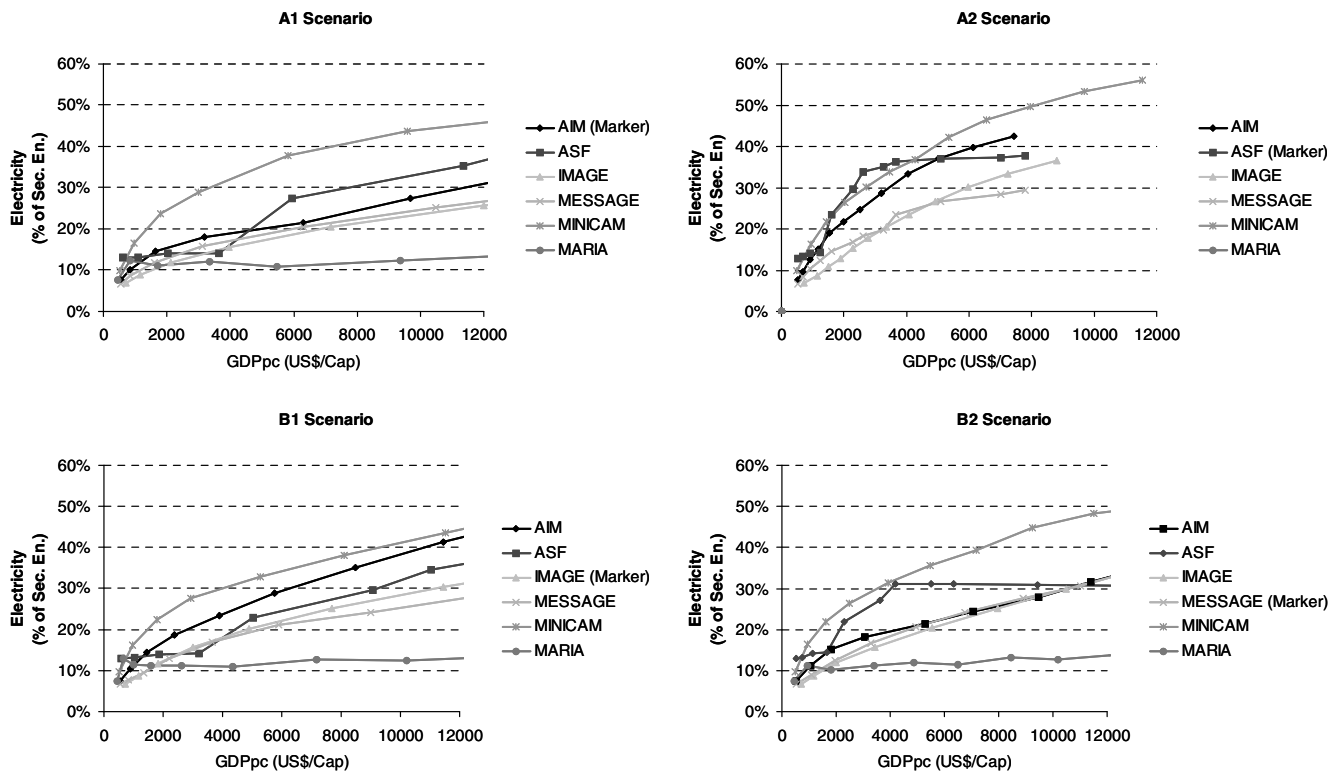

Figure 2. Fraction of electricity in secondary energy use versus GDP/capita in MER for the region of ASIA from the SRES models.

on the ladder is related to specific processes and driving forces. For instance, the transition from traditional to commercial fuels has to do with income, household size, and wood or fuel availability; the choice between different commercial fuels is influenced by subsidies and taxes and the investment cost for related equipment; and the use of electricity is only possible once households are connected to the grid, or have stand-alone electricity production. These issues, especially traditional fuels and electrification, are often not explicitly incorporated in the global energy models (see Table 1).

\section{(b) The environmental Kuznets curve in the SRES models}

The concept of the Environmental Kuznets Curve (EKC) generalizes environmental pressure in relation to economic development as an inverted U-shaped curve, analogous to the income inequality curve described by Kuznets (Kuznets, 1955). Based on the concept of the EKC, it is often argued that environmental pressure will decrease once developing countries become more prosperous (Beckerman, 1992). However, the empirical and statistical basis for the $\mathrm{EKC}$ is ambiguous results differ for different types of environmental pressure and time periods. Moreover, critics urge to focus on decom- position of the underlying processes that drive the generic concept (Focacci, 2005; Gales, Kander, Malanima, \& Rubio, 2007; Stern, 2004). In this context, also the value for modeling energyrelated emissions in developing countries is questioned, referring to the heterogeneous income distribution, large presence of poor regions, prevailing rural lifestyle and economic and social barriers to the widespread adaptation of technologies (Focacci, 2005). Diversity and confusion in the EKC-debate stem, among others, from the many definitions that are used to indicate environmental pressure (emissions, either absolute $(\mathrm{kg})$, per capita $(\mathrm{kg} / \mathrm{cap})$ or as intensity $(\mathrm{kg} / \$)$, or concentrations $\left.\left(\mathrm{kg} / \mathrm{m}^{3}\right)\right)$ and even the use of underlying drivers such as energy use (or intensity) and carbon emissions (or intensity). While evidence is relatively strong for EKC-type trends in the case of for instance absolute $\mathrm{SO}_{2}$ emissions, for $\mathrm{CO}_{2}$ emissions there is hardly any evidence that the EKC holds (see further). The application of the EKC concept for $\mathrm{CO}_{2}$ is in the case of developing countries further complicated because traditional fuels can distort the shape of the curve: the long-term trend of energy intensity can be declining (traditional fuel use is very inefficient), whereas carbon intensity is increasing because fuel wood, which does not result in net $\mathrm{CO}_{2}$ emissions (depending on the sustainability of the source), 
is substituted by fossil fuels (Gales et al., 2007) (see also Section 3). ${ }^{5}$

We evaluate the results of the IPCC/SRES models with respect to the EKC using two environmental pressure indicators: sulfur and carbon emissions per capita. For sulfur emissions, there is a generic trend in all models to follow an EKC, although the turning point of the inverted U-shape is different (Figure 3). The wide variation between the models, even though income, population, and energy use projections were coordinated with the marker model, can be explained from different structures in the energy systems (mainly the applied technologies/ fuels) or exogenous assumptions on emission intensity. In the $\mathrm{A} 1, \mathrm{~B} 1$, and $\mathrm{A} 2$ scenarios, the ASF model has the highest $\mathrm{SO}_{x}$ emissions, which can be explained from the model's strong focus on coal (van der Sluijs et al., 2001). In the regionalized A2 scenario, the AIM model projects high coal use for Asia, and shows correspondingly high $\mathrm{SO}_{x}$ emissions. Sulfur emissions of the IMAGE and MESSAGE models show wide variations between different scenarios.

There is discussion whether an EKC-type of trajectory could also apply to carbon emissions (Quadrelli \& Peterson, 2007; Raupach et al., 2007). For $\mathrm{CO}_{2}$ so-far there is no evidence of an absolute decoupling of rising incomes and rising $\mathrm{CO}_{2}$ emissions (so no turning point below current Western income levels): some sectors show signs of saturation of energy use, while in other sectors energy use is still growing rapidly. In this context, we have increased the upper limit of the income axis in Figure 4, in order to at least plot the behavior of the model results at higher income levels. Also for carbon emissions, wide variations exist between models and scenarios (Figure 4). It should be noted that none of the models have explicitly included the EKC as a theoretical concept to model trends in $\mathrm{CO}_{2}$ emissions - and trends are driven by factors such as energy demand, exploration, and depletion of fossil fuels and technology development. Nevertheless, it is interesting to follow depicted trends in this context. The A2 scenario does not show a turning point of the EKC in the 21st century, while the B1 scenario indicates a turning point well below an Asian average level of 10,000 US\$/capita. The ASF model shows the highest carbon emissions in all scenarios, which can be explained from its focus on coal. The AIM model also projects a high share of coal, and thus relatively high $\mathrm{CO}_{2}$ emissions in regionalizing scenarios. Very low carbon emissions are projected by the MARIA model, due to the substantial amount of nuclear energy projected here (IPCC, 2000b; van der Sluijs et al., 2001).

Generally, all model results show the inverted U-shape of the EKC in the A1 and B1 scenarios for both sulfur and carbon emissions per capita. Higher turning points for the A2 and B2 scenarios were also found in an analysis of the

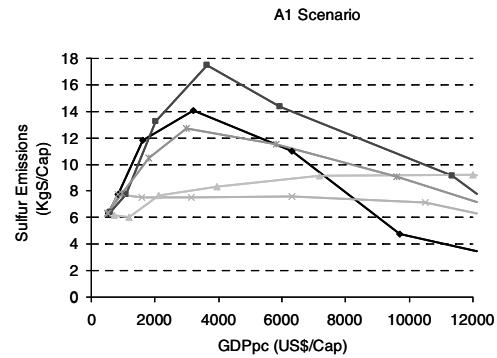

B1 Scenario

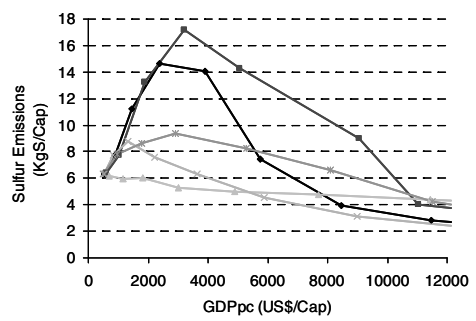

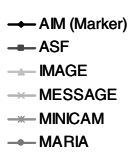

$\rightarrow$ AIM

- IMAGE (Marker)

-MESSAGE

$\rightarrow$ MINICAM

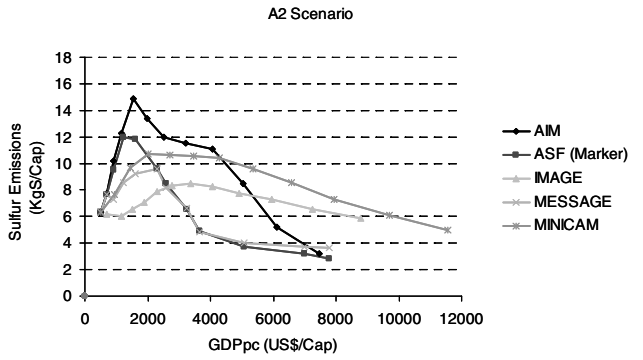

B2 Scenario

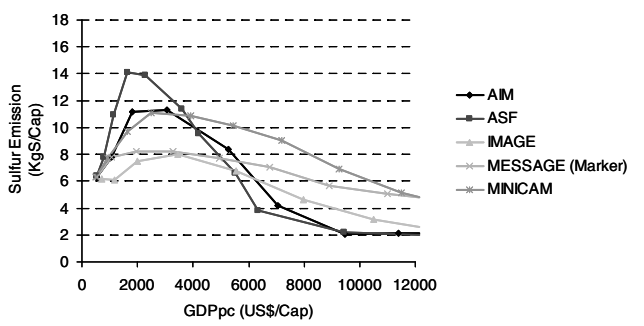

Figure 3. Sulfur emission projections versus GDP/capita in MER for ASIA from the IPCC/SRES models. 

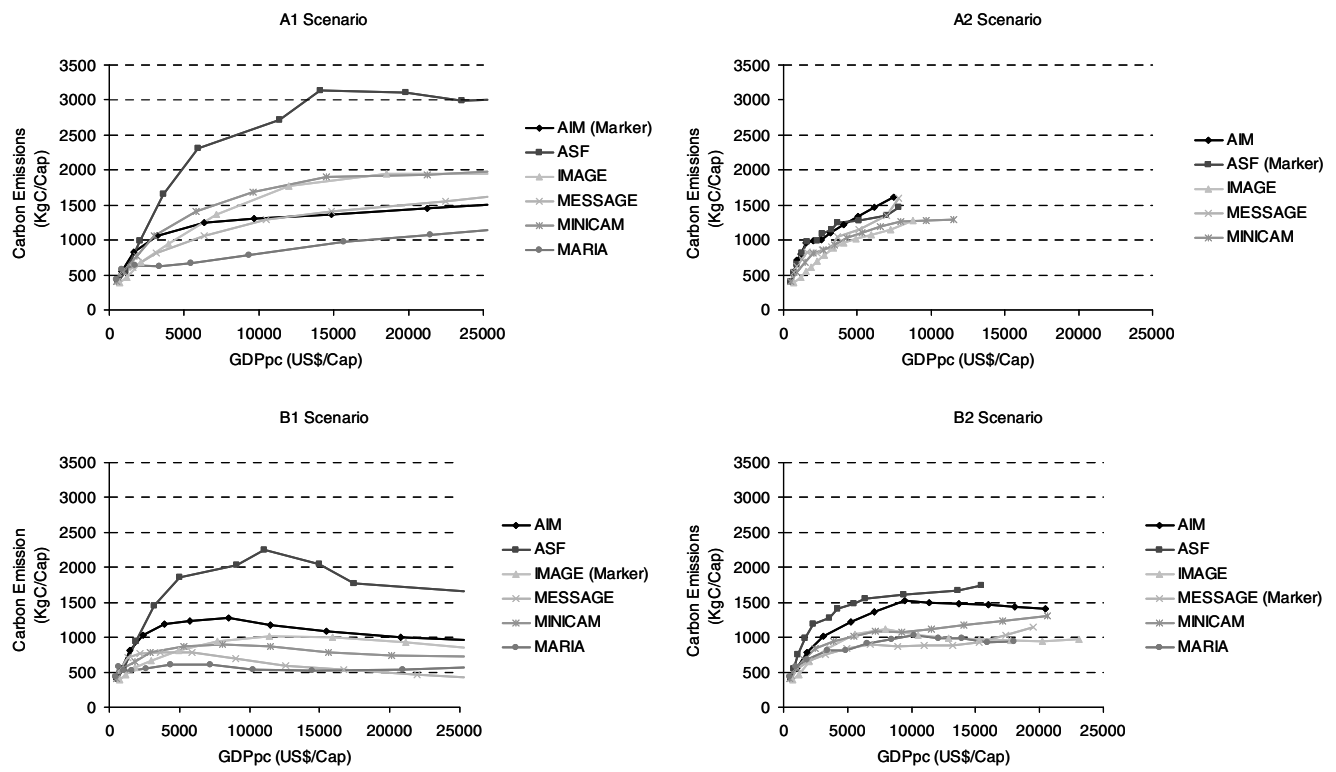

Figure 4. Carbon emission projections versus GDP/capita in MER for ASIA from the IPCC/SRES models.

EKC in the IPCC/SRES models at the global level (Fonkych \& Lempert, 2005). For $\mathrm{SO}_{x}$ emissions, industrialized countries have restrictive policies since the 1970s and end-of-pipe technologies are widely applied. Diffusion of these policies and technologies toward developing countries takes place and is expected to continue (Grubler, 2002; Smith, Pitcher, \& Wigley, 2005). The SRES results of the A1 and B1 scenarios show a pattern for $\mathrm{CO}_{2}$ emissions at the Asian level that is consistent with the EKC concept. However, carbon mitigation policies were explicitly excluded from the scenarios and the existence of such curve is debated in the literature; it remains at best doubtful whether the EKC is a useful concept to describe trends in $\mathrm{CO}_{2}$ emissions. The underlying processes that determine whether developing countries follow the EKC, for example, heterogeneous income distribution, rural-urban divide or socio-economic barriers (Focacci, 2005), but also carbon emission of fuel wood (Gales et al., 2007), are rarely explicitly modeled in the SRES global energy models (see Table 1).

\section{KEY-ISSUES OF ENERGY SYSTEMS IN DEVELOPING COUNTRIES}

Based on the analysis of the model results with respect to the energy ladder and the
EKC, we can distinguish three groups of key-issues that were less relevant for energy systems in industrialized regions (in recent history), but are of importance for today's developing countries. First, key-issues in the energy system itself are the use of traditional fuels and limited access to modern energy (electrification), both related to the energy ladder. A second group of issues, involving structural change, income distribution, and the role of the informal economy, has a more socio-economic nature and is related to the demand for energy. A third group of issues is related to the context of development for present-day developing countries compared to Western regions after 1960 and involves depletion of resources, climate change, and local air pollution. A final issue is the difference between urban and rural areas. Most global energy models do not make a differentiation between urban and rural energy systems, although for most of the above identified key-issues, urban and rural characteristics are different. Therefore, we discuss this with the key-issues below.

Are these key-issues incorporated in the IPCC/SRES models? We assess this question qualitatively, based on the IPCC/SRES report (IPCC, 2000a), the available model documentation from the time of the SRES (de Vries, van Vuuren, den Elzen, \& Janssen, 2001; Kainuma, Matsuoka, \& Morita, 2003; Mori, 2000) and an overview of the SRES models structure (van 
der Sluijs et al., 2001) (see Table 1). Below, we elaborate on the key-issues, evaluate whether and how they are incorporated in the SRES models and discuss their relevance for global energy models.

(a) Developments in the energy system

\section{(i) Transition from traditional to commercial fuels}

Traditional biomass, such as fuel wood, dung, agricultural waste, crop residues and charcoal constitute a major source of energy in the developing world. In $2000,52 \%$ of the total population of developing countries relied on traditional biomass as the main source of energy for cooking and heating (IEA, 2002). Traditional biomass combustion causes indoor air pollution which triggers various adverse health effects and an estimated 1.6 million deaths per year (WHO, 2006). Issues related to fuel wood are limited availability and impact on deforestation (Arnold, Kohlin, \& Persson, 2006).
Data and stylized facts. Official statistics on fuel wood include only production, not consumption (FAO, 2005) (but they can easily be considered equal). Unfortunately, however, the reliability of statistics on this topic can be questioned, as most fuel wood is gathered from woodlands and never accounted for in statistics. Another data problem concerning traditional fuel is that global statistic databases account only for fuel wood, not for other forms of traditional biomass; dung, agricultural waste and crop residues are only taken into account by survey studies (FAO, 2005; Xiaohua \& Zhenmin, 2005).

Given these caveats, the available data show a generally decreasing trend in fuel wood production per capita with increasing income levels in all world regions and several Asian countries (Figures 5 and 6, left graphs). Sub-Saharan Africa also shows a decline in per capita fuel wood production in time, although it faced a decreasing GDP/capita (PPP) in the described period, indicating the relevance of other drivers
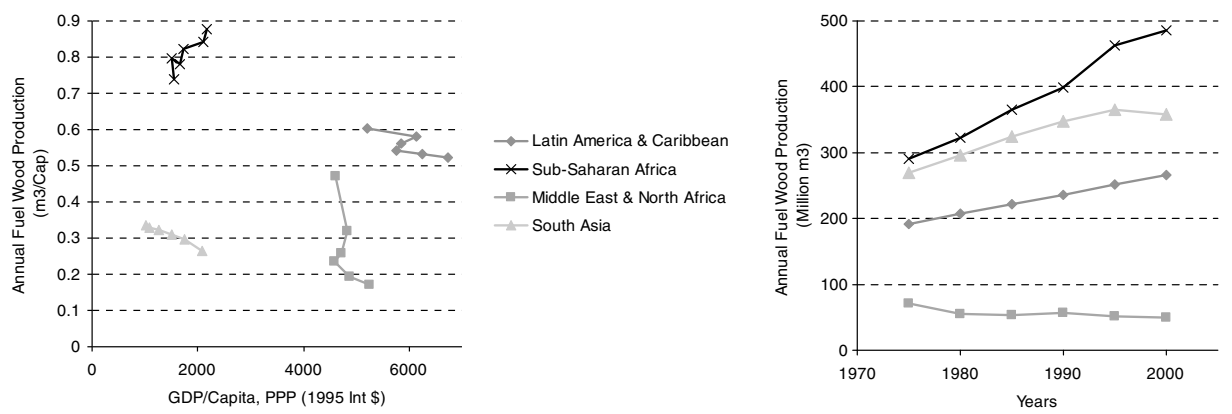

Figure 5. Left: Fuel wood production per capita versus GDP/capita (PPP) for several developing world regions, data from 1975 to 2000. Right: Absolute annual fuel wood production for several developing world regions. Data from FAO (2005) and World Bank, 2004.
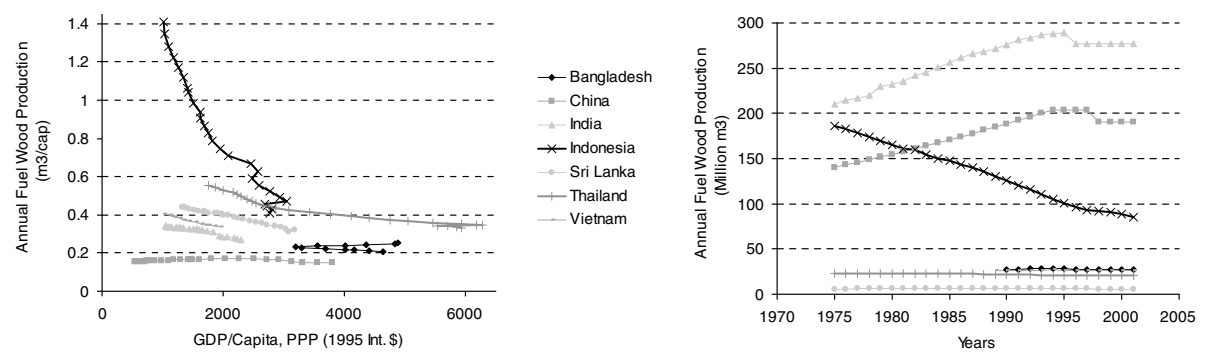

Figure 6. left: Fuel wood production per capita versus GDP/capita (PPP) for several Asian countries for the period 1975-2000. Right: Absolute annual fuel wood production for several Asian countries. Data from FAO (2005) and World Bank, 2004. 
than income. In contrast to per capita fuel wood production, absolute production increased in most world-regions and in most Asian countries (Figures 5 and 6, right graphs). This indicates increasing pressure of population growth on the natural environment and the fuel wood supply. As an exception Middle East and North Africa and Indonesia show a declining absolute fuel wood production level (and a rapidly declining per capita level); both regions have abundant oil resources and the Middle East and North Africa have little forest available.

Many studies exist on fuel switching and its relation to socio-economic development. Usually, a decreasing use of traditional fuels in relative measures is observed: per capita, but also as share of total energy use. An extensive data analysis was performed by Victor and Victor (2002). They found that declining fuel wood use can statistically mainly be explained from several factors: changes in income, differences in availability, degree of urbanization, and industrialization. Besides these main drivers, other factors that determine the use of traditional biomass are the costs of this energy source (e.g., costs for feedstock, conversion, or alternative fuels), culture and traditions, climate, geography, and land use. Culture and tradition are often ignored in energy modeling, as cultural habits are hard to quantify. The relation between income and fuel wood use may be better understood when income distribution is taken into account, as fuel wood is mainly used by lower income households (Victor \& Victor, 2002).

Relevance for global energy models. Only three of the IPCC/SRES models report the use of traditional fuels, two of them using a non-described method (Table 1). This means that the models ignore an essential element of the energy system, potentially underestimating the demand for energy (and energy intensity). Although in terms of global energy use traditional fuels are not very important, there are several reasons to include them in global energy models. First, they constitute a substantial part of energy use in developing countries, especially relevant for people in rural areas. Second, they are not easily replaced as transport and distribution of alternative fuels are expensive in rural areas and cultural habits play a major role. Third, the contrast between declining per capita use and increasing total production of fuel wood in many regions expresses pressure on forests, shortages, and a potential fuel wood crisis (see e.g., Arnold et al., 2006). Global energy models could provide added value in this discussion, if they would link demand and supply of fuel wood and identify areas where problems might arise. Also, if fuel wood use is not sustainably harvested it leads to deforestation, a source of carbon emissions. Finally, the importance of traditional energy use for health issues is another reason to include this fuel type in the models.

\section{(ii) Electrification}

In the industrialized world almost every house is connected to the electricity grid, whereas in developing regions $64 \%$ of the population had access to electricity in 2000 (IEA, 2002). In residential energy use, a major difference exists between urban and rural areas; in urban areas electricity is often the predominant type of energy while rural areas depend more on traditional fuels (Figure 7 and Goldemberg, 2000; Reddy, 2000). Many remote villages, especially those in mountainous areas, are not connected to a central electricity grid.

Data and stylized facts. Data on electrification are scarce and their usefulness is limited as definitions for "access to electricity" differ per country (IEA, 2002). We used data from the World Energy Outlook (2002) to analyze stylized facts in the relation between development and electrification. These data strongly suggest that the higher the income, the higher the electrification rates. In fact, the electrification rate increases fast initially and then slows down as only remote areas are left to be electrified (see Figures 7 and 8).

Often, a positive feed-back loop is assumed between increased income and growing electricity rates. Increasing income levels lead to an increase of electrification rates, and investments in the electricity sector. At the same time, access to electricity allows to increase income generation as working and manufacturing are possible after dark. Also, more efficient electric machinery and equipment can be used leading to an overall increase in productivity and income. The last proposition does not necessarily needs to hold: first, many electrification projects do not offer further service or maintenance after the projects end, wiping out the advantages of electrification (Mulugetta, Nhete, \& Jackson, 2000). Second, access to electricity is only one of many barriers for economic development; market development and access, finan- 


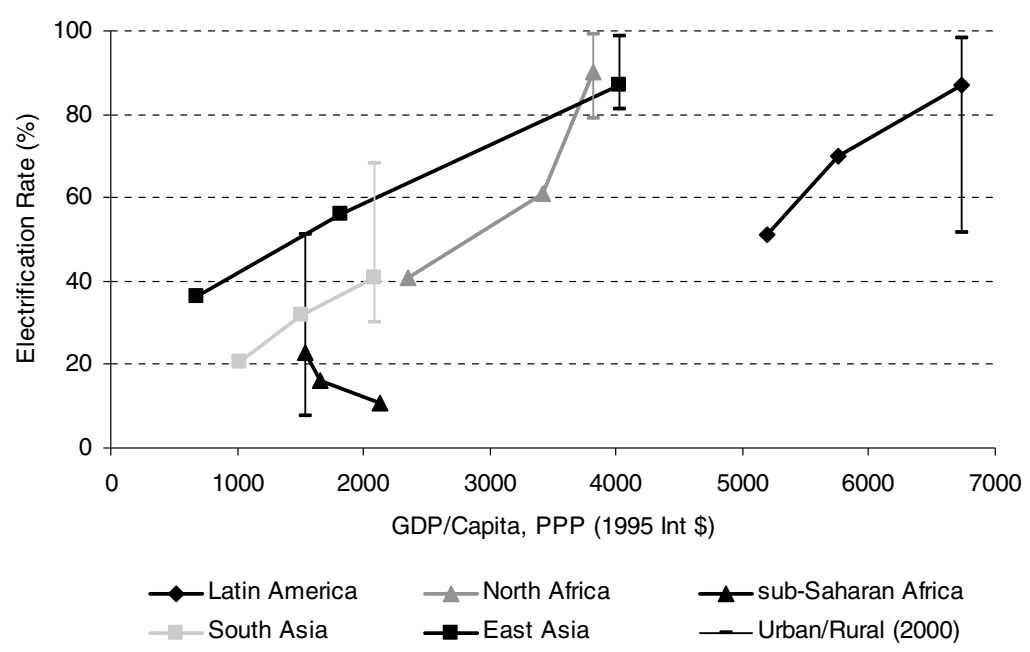

Figure 7. Electrification rates in several developing regions versus GDP/capita (PPP). Data points are for 1975, 1990, and 2000. For the year 2000 information on urban and rural electrification is added, in all regions urban electrification rates are higher than rural. Note that sub-Saharan Africa faced a declining GDP/capita over the described period. Data from IEA, 2002 and World Bank WDI, 2004.
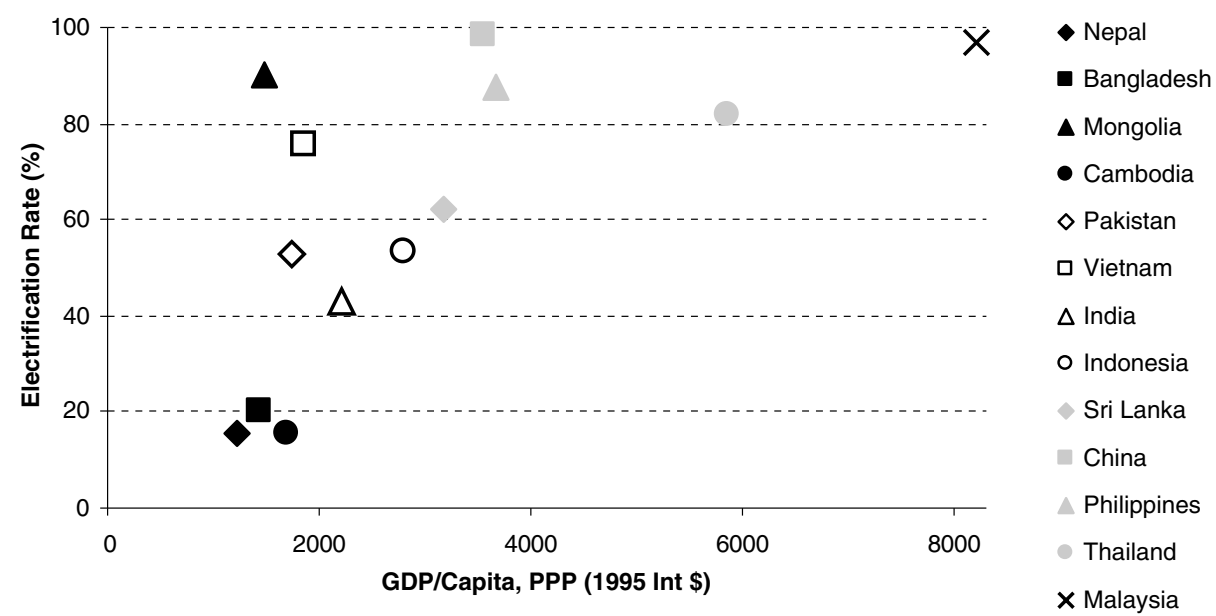

Figure 8. Electrification rates in several Asian developing countries versus GDP/capita (PPP) for the year 2000. Data source: IEA, 2002 and World Bank WDI 2004.

cial services (credit) and client's willingness to pay for quality products are also of importance for small manufacturing enterprises (Kooijman, 2005).

Relevance for global energy models. As far as could be extracted from documentation of the IPCC/SRES models none of the models deal explicitly with electrification processes
(Table 1). ${ }^{6}$ These models implicitly assume that increasing electrification rates are included in the increasing demand for electricity with rising economic activity. This is not necessarily incorrect, but it increases uncertainty of projections for the level of energy demand in developing countries. Electrification (especially if interpreted as grid-expansion) influences primary energy use, since grid or non-grid electric- 
ity is generated by different technologies. Nongrid electricity is typically from small-scale renewable energy or oil generators and griddelivered electricity is from large-scale sources; coal, gas, and nuclear. Secondly, the electrification process (grid expansion) is a very capital intensive process and the implicit way of describing electrification in these models may not capture the possible limitations posed by access to capital and economic viability.

(b) From economic development to energy use

(i) Economic structural change and dematerialization

It is often observed that the nature of economic value added and employment shifts during the development of economies. Typically, developing economies are characterized by a large share of the population working in agriculture (see Figure 9, left graph). Historically, developing countries that changed into an industrial economy did this by increasing the production of labor intensive export products. Taiwan, Singapore, Korea, and Hong Kong are historic examples; nowadays China and India show a similar pattern. In a later stage the share of the service sector increases in value added and employment. This stage has been observed in developed economies, during the second half of the 20th century. This description of economic structural changes is highly stylized, and it is questionable whether it can be directly applied for individual countries (Jung, La Rovere, Gaj, Shukla, \& Zhou, 2000). Criticism on this concept is recently formulated by historic economists, mainly regarding the shift toward the service sector. For
Sweden it was found that, when measured in constant prices per sector, the share of the service sector has been fairly constant over the last two centuries, while the share of industry increased at the expense of the agricultural sector (Kander, 2005). Also, India has a remarkably high share of services (see Figure 11, and de Vries, Revi, Bhat, Hilderink, \& Lucas, 2007), which influences the prospects for scenario development. Another reason why developing country development might be different is that the decline in the industrial section in developed countries is partly caused by a replacement of (heavy) industry from high to low income countries. Such "outsourcing" of industry can obviously not be reproduced by countries that currently have the lowest income levels.

A concept that can be related to economic structural change is the long-term trend of dematerialization. The theory of dematerialization can be summarized in two elements: (1) the intensity of use (in $\mathrm{kg} / \mathrm{S}$ of a given material or energy) follows a similar pattern for all economies, first increasing with per capita GDP, reaching a maximum and than declining (see Figure 9, right graph); (2) the maximum intensity of use declines the later in time it is attained by a given economy (Bernardini \& Galli, 1993; Reddy \& Goldemberg, 1990). Besides structural change, this pattern is often explained from technical improvements that decrease material input, substitution of new materials with better properties, saturation of bulk markets for basic materials and government regulations (Cleveland \& Ruth, 1998). The strength of this concept is its simplicity, the weakness is that technologies and material substitution do not necessarily depend primarily on per capita
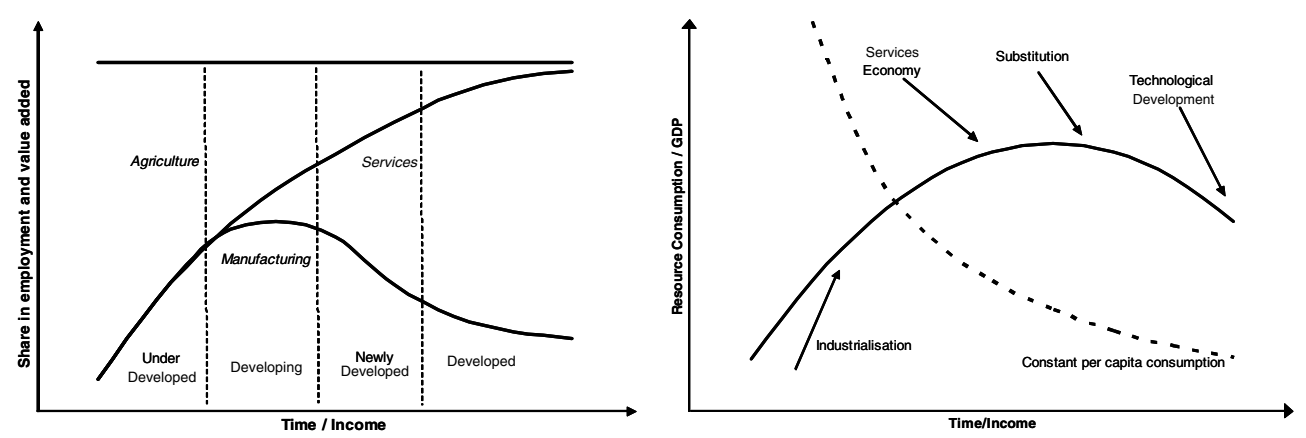

Figure 9. Left, typical stages in the share of employment or value added of agriculture, manufacturing and services, based on (Jung et al., 2000) and right, the typical intensity of use curve of resources with economic development, based on (van Vuuren et al., 1999). 
income and that it does not include the relevant driving forces (van Vuuren, Strengers, \& De Vries, 1999). Including or excluding traditional fuels can change the long-term pattern of energy intensity (Gales et al., 2007) and leads to different estimations of energy use in developing countries.

The question is whether these patterns hold true for the future of developing regions. These regions may catch up with new, less materialand energy-intensive technology (leapfrogging) or show different patterns of economic structural change. One indication that this might happen is that countries which developed their industry and energy system in the 20th century show lower $\mathrm{CO}_{2}$ intensity curves than earlier industrialized countries, due to leapfrogging over the carbon intensive coal-period (Lindmark, 2004).

Data and stylized facts. Data analysis for the period 1975-2000 shows that, on average, low-income economies depend largely on agriculture, middle income countries have a relatively high share of industry and high income countries have a high share of services (Figure 10, left graph). However, in all income classes the share of industry decreases and services increases. Energy intensity decreases in all classes, which is likely to be related to both the rising share of services and improvements in energy efficiency.

At the same time, the values for value added and energy intensity of the two major Asian developing countries, China and India, are completely different (Figure 11). By 2000, the Indian GDP was for more than $50 \%$ based on services, while China relied for $50 \%$ on industry. Energy intensity decreased in both coun- tries, in China faster than in India, although the energy intensity for India is already relatively low compared to other low-income countries (see Figure 10). Obviously, differences in the energy intensity of the total economy can not only be explained from different economic structures; for instance, the applied technologies and policies, but also climate differences and population density, play a role.

Relevance for global energy models. Economic structural change and energy intensity play a major role in energy demand projections, but differences between countries make it hard to apply these concepts in general in global energy models. All IPCC/SRES models distinguish several economic sectors and therefore it is likely that some form of structural change is included by applying sector-specific economic drivers for energy use (Table 1). However, the agriculture sector, which is dominant in economic terms in most developing regions and uses electricity for irrigation, is seldomly modeled explicitly. Also, changes in energy intensity within economic sectors are only included in some models, see, for example, the TIMER model (de Vries et al., 2001).

\section{(ii) Income distribution}

A difference between developed and developing countries is the distribution of income over the population. Developing countries tend to have a more unequal income distribution, indicating a division in societies between rich elites and poor masses. The classical concept is that with increasing economic development, income inequality would initially increase and, after a top-level, decrease (Kuznets, 1955). Since 1955, studies have been published that reject,
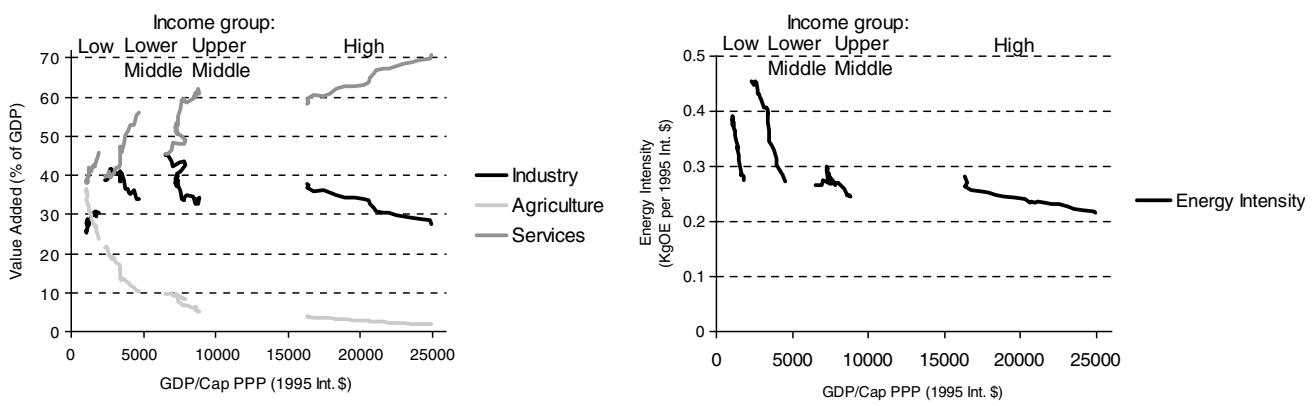

Figure 10. Value added (left) and primary commercial energy intensity (right) versus GDP/capita (PPP) for low income, lower middle income, upper middle income and high income countries (1975-2000, data from World Bank 

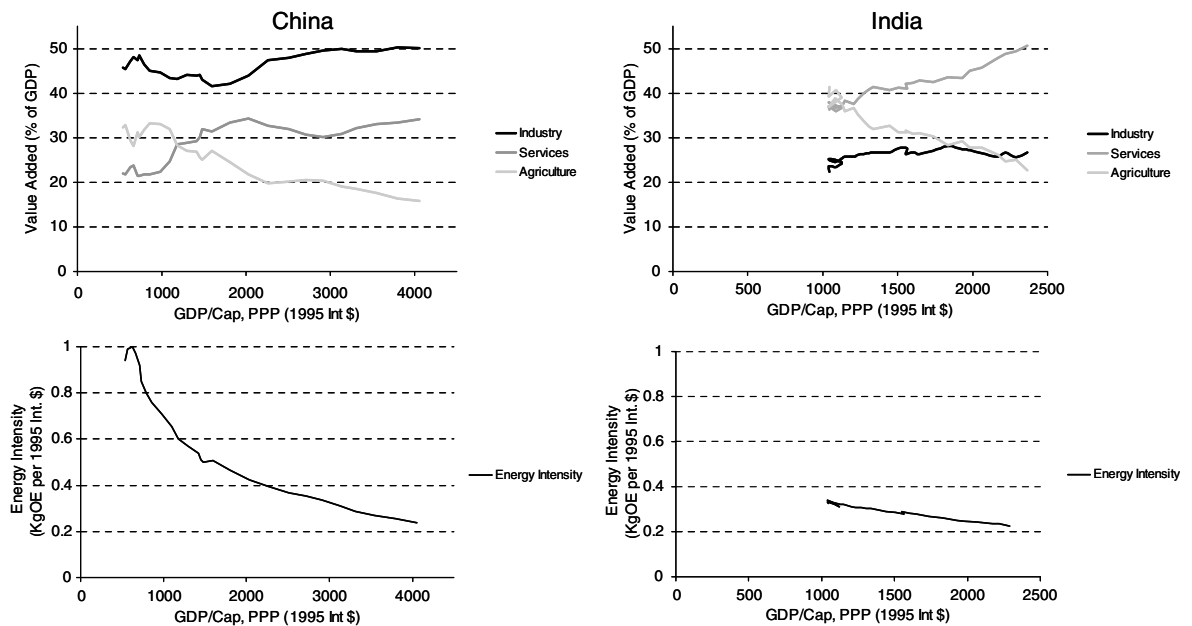

Figure 11. value added (upper) and primary commercial energy intensity (lower) versus GDP/capita for India and China from 1975-2002, data from World Bank (2004).

affirm or discuss this stylized fact of increasing and decreasing income inequality (see e.g., Glomm, 1997; Saith, 1983).

Data and stylized facts. Data on income inequality are scarce. We used the GINI coefficient as available in the World Bank WDI (World Bank, 2004) as numerical measure for the degree of inequality of income. ${ }^{7}$ It appears that income distribution generally tends to become more equal with increasing GDP/capita
(Figure 12). However, a stylized function for this development, like a Kuznets curve, cannot be extracted from these data. What can be noted, though, is that developing countries have a much higher variation in income distribution than developed countries.

Relevance for global energy models. Income distribution is not incorporated in the SRES models (see Table 1). Energy demand is mostly modeled as a function of the average GDP per

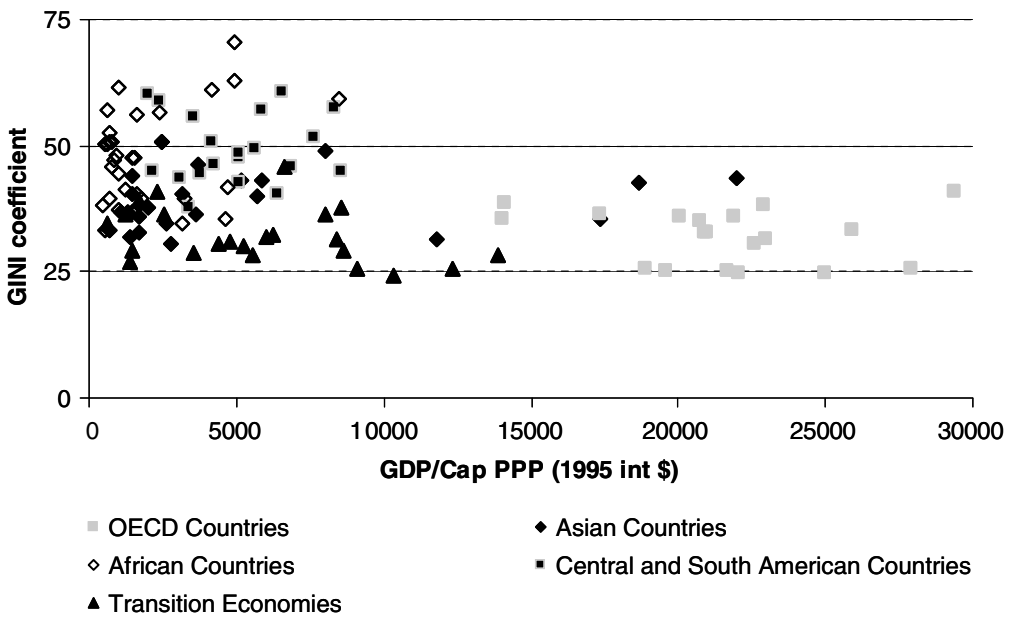

Figure 12. GINI coefficients versus GDP/capita (PPP) for 121 countries. A higher GINI coefficient indicates a more unequal income distribution. Data for different years during 1990-2001, from World Bank (2004). 
capita and changes in income distribution (e.g., the development of a middle class and matching lifestyle) are not necessarily reflected in this indicator. Initial research indicates that income distribution could be an important factor in transport energy demand but more research is needed to explore this topic for long-term global energy modeling (Storchmann, 2005). In this respect, it is important to realize that independent modeling of high and low income groups may result in very different dynamic behavior than suggested by the averages (see van Vuuren et al., 1999 for an example with high and low income regions). A tentative indication is that models that ignore income distribution differences in developing countries tend to underestimate energy behavior that is typically related to low- or high-income groups, for example, the use of traditional energy or the electricity and transport behavior of high income households.

A complicating factor for including income distribution in energy modeling is the availability and quality of data. Long-term time series are rare, measuring is not consistent and future projections are not provided by macro-economic models. Another pitfall is the possible interference with other developments, like urbanization and decreasing household size. However, it could be worthwhile to attempt as it adds a new dynamic process to global energy models; the available data provide a starting-point and future assumptions can be part of a scenario storyline.

\section{(iii) Informal economic systems}

Most energy models use GDP per capita as a driver for energy use. Apart from the issue of the underestimation of economies of developing countries using market-exchange rate data (which can be solved by using PPP data, see further), GDP may still not be a good indicator for the energy intensity of activities, as developing countries have a large informal sector. This informal economy involves the unofficial transactions that take place in the real world, but that are not reflected in official economic descriptions. It is a broad concept, for which different scientists use different definitions, including or excluding illegal activities, tax evasion and monetary and non-monetary transactions (Schneider, 2005). The main "drivers" for the informal economy appear to be the tax burden and social security contributions, the intensity of regulations, social transfer systems, overregulation, and high cost on the offi- cial labor market (Schneider \& Enste, 2000). Informal economies exist all over the world, but in developing countries the informal economy usually forms a much larger share of the total economy (Chaudhuri, Schneider, \& Chattopadhyay, 2006; Kahn \& Pfaff, 2000): on average in $1999-200041 \%$ of the total official GDP, against an average of $17 \%$ in OECD-countries (Schneider, 2005).

Data and stylized facts. The main problem of informal transactions is that they are hard to measure; data have to be derived from indirect indicators. Several methods exist to assess the size of the informal economy. The direct approach uses surveys and samples, but its reliability might be weak. Indirect methods use discrepancies between several statistics, for instance, between national expenditures and income statistics. More advanced methods use the expected amount of transactions in the economy or look into the physical input of the economy (e.g., electricity) as an indicator for the real economic activity. The DYMIMIC model approach (Schneider, 2005) uses multiple input and output indicators to estimate and explain the size of the informal economy.

Figure 13 shows estimations of the size of the informal economy for a global set of countries, clustered in world regions. Also on a country basis, estimations for OECD countries are generally much lower and show less variation than developing countries (as indicated by the arrows). Over time, the size of the shadow economy increased in all countries during the 1990s, also the OECD countries. This may be a consequence of increasing burdens of taxation and social security payments, combined with rising state regulatory activities (Schneider, 2005, 2006).

Relevance for global energy models. The existence of informal economic systems is of importance for global energy modeling as it indicates that the official economic activity (GDP/capi$t a$ ), often used as driving force for energy demand, does not reflect actual economic activity. Usually, the actual economic activity is higher, indicating a different relation between economic activity and energy demand. The cross-country observation of a declining informal economy with increasing income (arrows in Figure 13) indicates a process of "formalizing" the economy. If informal activities are formalized, the official economic growth is artificially high and energy intensity (in GJ 


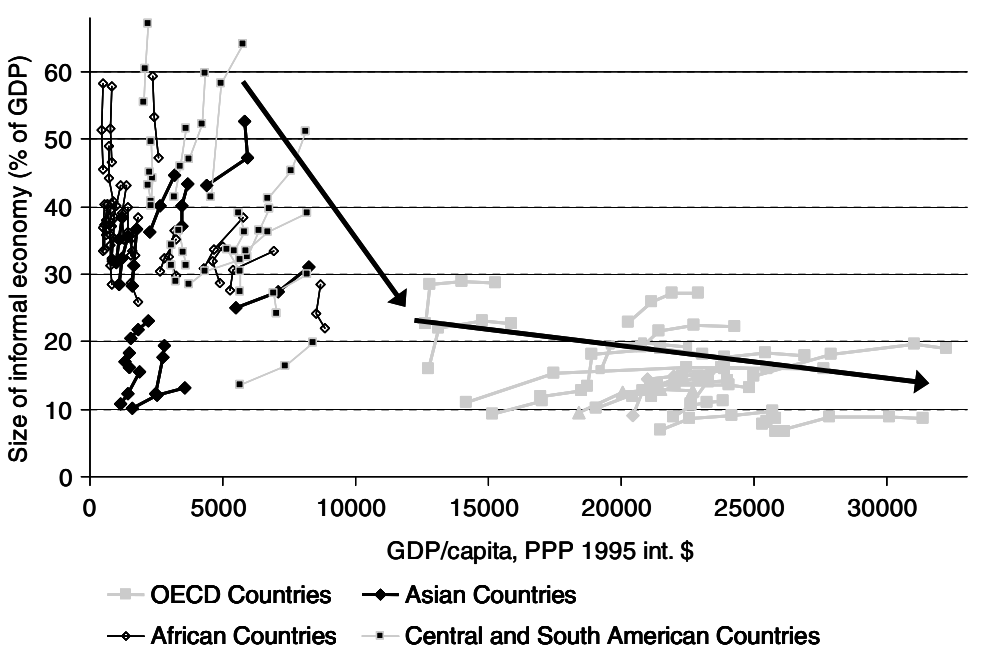

Figure 13. Estimations of the size of the shadow economy for several countries versus GDP/capita (PPP). Data from World Bank, 2004 and Schneider, 2005; data points for developing regions: 1990/1991, 1994/1995, and 1999/2000, for OECD regions: 1989/1990, 1994/1995, 1997/1998, and 1999/2000.

per official dollar) decreases rapidly. See, for example, Figure 11, in which China and India show rapidly declining energy intensities; this might also be explained from formalization (or monetization) of the economy. As energy intensity numbers are often interpreted in terms of energy efficiency - estimates for improvement in developing countries might be overestimated.

Informal economic systems are not included in the SRES models (see Table 1). Clearly, there is a relationship between the discussion on the correct metric of GDP data (PPP versus MER, see Section 1) and the size of the informal economy. One possible explanation of the large differences in the PPP/MER ratio is that informal economic activities decrease the prices of tradable services and goods also on the official market, increasing the purchasing power of consumers. The relation between PPP and the informal economy is unfortunately barely understood (Schneider, 2006) - and alternative explanations for high PPP/MER ratios also exist (van Vuuren \& Alfsen, 2006).

\section{(c) The context of development}

An implicit assumption of many global energy models is that the future of developing regions can be derived from experiences during the last decades in industrialized regions. This focus on only the recent past of industrialized regions (for practical reasons), unfortunately implies that potentially valuable information from the times that Western countries were at the economic activity level (but not technology level) of present-day developing countries is not often used to develop insights in developing countries trends. Above, we discussed some characteristics of energy systems and socio-economic developments that mark the difference between developed and developing regions. A final series of issues is related to the context in which energy systems are developing: depletion of fossil resources, climate change, and local air pollution. These issues are not unique for developing regions (high energy prices and air pollution were also relevant for Western countries in the 19th century) but they might drive energy systems in developing countries in a different direction than industrialized regions since 1960. Generally, these issues are more elaborately included in global energy models than the issues discussed above (see Table 1).

\section{(i) Fossil energy resource depletion}

The issue of resource depletion and increasing energy costs is included in all SRES models, mostly based on a single fossil resource assessment (Rogner, 1997) (see Table 1). This is the most straightforward impact of resource deple- 
tion: some energy sources become more expensive upon depletion, causing a shift toward competitive alternatives. A second impact is the feedback of rising long-term energy costs (or at least a break with the long-term decline) on economic development, a process that can only be modeled in integrated energy-economy models (many of the SRES models are partial equilibrium models and do not capture this feedback). The question here is whether experiences during the oil crisis can be used to model expected future depletion of fossil resources. It should be noted that as oil-importing developing countries have a higher energy intensity, they are much more vulnerable to energy price increases than Western countries (Lucon et al., 2006; Srivastava \& Misra, 2007). At the same time, long-term economic history shows that energy prices were also relatively high during the early stages of economic development in Western countries (Kander, 2002); this period might provide valuable lessons to global energy models.

\section{(ii) Climate change}

Historically, climate change has hardly had any impact on the development of energy systems, in both developing and industrialized regions. However, since energy use is responsible for the majority of greenhouse gas emissions and climate change is expected to influence economic development (Halsnæs, Kühl, \& Olesen, 2007; O'Brien et al., 2004), it becomes a relevant issue for energy systems in developing countries. Climate change can have two major impacts on the development of the energy system. One is that changes in climate can lead to changes in energy demand projections (e.g., higher cooling demand) or to constraints in energy production (e.g. operational requirements in power plants). A much more relevant impact, however, is the impact of climate policy on energy system development. Model studies stress the importance of involving developing countries in international climate policy-in order to avoid high costs and to keep ambitious climate policy targets attainable (e.g., van Vuuren et al., 2007). However, as energy technologies with low or zero greenhouse gas emissions are usually more expensive than their fossil-fuel alternatives this raises the issue who will pay for these additional costs. At the moment, the position of developing countries in international negotiations is that the additional burden of climate policy would damage their abilities for development. Current models are in principle well equipped to assess the additional costs of mitigation trajectories, also on a regional basis (including different proposals for differentiation of commitments among developed and developing countries). There are, however, open issues with respect to additional implementation barriers (e.g. information, risk) in developing countries that are poorly captured by these models. In any case, climate policy might put developing (and developed) countries on a different trajectory than observed historically.

\section{(iii) Urban air pollution}

One of the major present-day energy-related problems in developing countries is urban air pollution. During the industrial revolution, Western countries also suffered from urban air pollution (Mosley, 2001) and more recently other forms of regional air pollution (e.g. acidification). Especially in the last decades, these problems have been solved using end-of-pipe technology for sulfur emissions, volatile organic compounds and nitrous oxides. Since most of these technologies are affordable and available in developing regions, this issue alone might not be very decisive on the future development of energy systems. However, if combined with climate policy (e.g. van Vuuren et al., 2006) or if renewable energy is promoted as a solution (e.g. Boudri et al., 2002), urban air pollution can benefit from other developments in the energy system that have an impact on the energy system structure. Interestingly, the link could also work the other way around. While historically, end-of-pipe solutions have been favored, integrated consideration of both air pollution and climate policy objectives, could lead to a preference for energy efficiency and low-greenhouse gas energy supply options driven primarily by the desire to reduce health impacts of air pollution (Bollen, van der Zwaan, Eerens, \& Brink, 2007).

\section{DISCUSSION AND CONCLUSION}

In this article, we have discussed the handling of developing countries in energy-climate models, suggesting that, given the increasing importance of developing countries, these models might need to be reformulated to better capture the dynamics of developing country energy systems. Obviously, the need of focus meant that 
we have focused on only a selection of the issues that are relevant in this context. Other key-issues like development of infrastructure or technology leapfrogging could have been discussed as well. Also examples of only a limited set of models (the IPCC/SRES models) have been used as they represented a useful consistent scenario database. The choice of models influences the results, but to our experience most discussed issues are not well captured in other global energy models either (Urban et al., 2007). Most data used in this article are derived from global databases: the World Bank WDI, the FAO statistical database, the IEA world energy outlook. These data are harmonized and comparable between countries, but insight in the reliability and collecting methods is generally weak. Finally, global energy models are (also) used to support a wide range of policy-making and weakness in modeling the energy systems of developing countries might lead to inaccuracies in policy-making. However, it is at this stage not possible to speculate about what the inclusion of the developing country issues in global energy models would mean for the results. Many of these issues have implications that work in two directions, both increasing and decreasing energy use and GHG emissions.

In this study, we found that the results of the IPCC/SRES global energy models for Asia are consistent with general "energy development" theories such as the environmental Kuznets curve and the energy ladder. Although some of the driving forces behind these concepts are already included in these models, several improvements, for example, on traditional fuel use, electrification, structural change, income distribution, the informal economy, and a feedback of climate change on the economy can increase their credibility for changes in the energy systems of developing countries.

The modeling of traditional energy, which is currently only done in three of the SRES models, can be improved by including wood-supply. This could be linked to forestation policies and health policies related to indoor air pollution. Explicitly accounting for electrification might improve the quality of projections on energy demand and technology choices for electricity generation. This could be related to electrification policies and the role of off-grid (renewable) energy systems. Economic structural change seems to be included in all SRES models, but the agriculture sector is not explicitly modeled. Modeling income distribution and rural/urban differences gains more insight in the impact of different lifestyles. Establishing a relation between different income groups, their behavior toward energy use and linking this to incomerelated energy pricing could be useful. Modeling the role of the informal economy might be useful, but seems not possible with current knowledge. Modeling the impacts of climate policy and climate change on the economy could be valuable to enhance insight in suitable GHG reduction mechanisms and their full effects.

\section{NOTES}

1. Due to different regional aggregations of the SRES models, the final report used only four regions: REF (economic reforming countries), OECD90, ASIA, and ALM (Africa and Latin America).

2. http://www.grida.no/climate/ipcc/emission/index.htm.

3. For reasons of comparability and to focus on the process of development (i.e. low incomes), we have chosen to limit the graphs to $12,000 \mathrm{US} \$ /$ capita, which is the maximum average Asian income level in the A2 scenario.

4. For the MARIA model, no A2 scenario was developed.
5. In the same way, modern renewable energy can decrease carbon intensity with constant energy intensity.

6. Research on more recent technical documentation and a questionnaire answered by the model developers indicates that in MESSAGE and MiniCAM electrification is modelled explicitly (Urban, Benders, \& Moll, 2007).

7. It is determined from two elements: (1) the Lorenz curve which ranks the empirical distribution of a variable and (2) the line of perfect equality in which each element has the same contribution to the total summation of the values of a variable (see, e.g., Cypher \& Dietz, 1997). Here, the GINI coefficient is given as a percentage and has values between zero (perfect equality) and 100 (perfect inequality). 


\section{REFERENCES}

Arnold, J. E. M., Kohlin, G., \& Persson, R. (2006). Woodfuels, livelihoods, and policy interventions: Changing perspectives. World Development, 34(3), 596-611.

Barnes, D. F., \& Floor, W. M. (1996). Rural energy in developing countries: A challenge for economic development. Annual Review of Energy and the Environment, 21(1), 497-530.

Beckerman, W. (1992). Economic growth and the environment: Whose growth? Whose environment? World Development, 20(4), 481-496.

Bernardini, O., \& Galli, R. (1993). Dematerialization: Long-term trends in the intensity of use of materials and energy. Futures, 25(4), 431-448.

Bollen, J., van der Zwaan, B., Eerens, H. E., \& Brink, C. (2007). Local air pollution and global climate change, a combined cost-benefit analysis (No. MNP Report 500116002/2007). Bilthoven: Netherlands Environmental Assessment Agency (MNP).

Boudri, J. C., Hordijk, L., Kroeze, C., Amann, M., Cofala, J., Bertok, I., et al. (2002). The potential contribution of renewable energy in air pollution abatement in China and India. Energy Policy, 30(5), 409-424.

Bouwman, A. F., Hartman, M. P. M., \& Klein Goldewijk, C. G. M. (Eds.) (2006). Integrated modelling of global environmental change. An overview of IMAGE 2.4. Bilthoven. The Netherlands: Netherlands Environmental Assessment Agency.

Brouwer, R., \& Falcao, M. P. M. P. (2004). Wood fuel consumption in Maputo, Mozambique. Biomass and Bioenergy, 27(3), 233-245.

Castles, I., \& Henderson, D. (2003). The IPCC emission scenarios: An economic-statistical critique. Energy \& Environment, 14(2-3), 159-185.

Chaudhuri, K., Schneider, F., \& Chattopadhyay, S. (2006). The size and development of the shadow economy: An empirical investigation from states of India. Journal of Development Economics, 80(2), $428-443$.

Cleveland, C. J., \& Ruth, M. (1998). Indicators of dematerialization and the materials intensity of use. Journal of Industrial Ecology, 2(3), 15-50.

Cypher, J. M., \& Dietz, J. L. (1997). The Process of Economic Development. London: Routledge.

de Vries, H. J. M., Revi, A., Bhat, G. K., Hilderink, H., \& Lucas, P. L. (2007). India 2050: Scenarios for an uncertain future (No. 550033002/2007). Bilithoven: Netherlands Environmental Assessment Agency (MNP).

de Vries, H. J. M., van Vuuren, D. P., den Elzen, M. G. J., \& Janssen, M. A. (2001). The TIMER IMage Energy Regional (TIMER) Model (No. 461502024/ 2001). Bilthoven: National Institute for Public Health and the Environment (RIVM).

FAO (2005). FAO Statistics Database (FAOSTAT). Retrieved February 22, 2006.

Focacci, A. (2005). Emperical analysis of the environmental and energy policies in some developing countries using widely employed macroeconomic indicators: the cases of Brazil, China and India. Energy Policy, 33, 543-554.

Fonkych, K., \& Lempert, R. (2005). Assessment of environmental kuznets curves and socioeconomic drivers in IPCC's SRES scenarios. The Journal of Environment Development, 14(1), 27-47.

Fujii, Y. (1993). The Evaluation of $\mathrm{CO}_{2}$ Mitigation Options in Energy System. Tokyo: Tokyo University.

Gales, B., Kander, A., Malanima, P., \& Rubio, M. (2007). North versus South: energy transition and energy intensity in Europe over 200 years. European Review of Economic History, 11(2), 219-253.

Glomm, G. (1997). Whatever happened to the Kuznets curve? Is it really upside down?. Journal of Income Distribution, 7(1), 63-87.

Goldemberg, J. (2000). Rural energy in developing countries. In J. Goldemberg (Ed.). World energy assessment, energy and the challange of sustainability. New York: UNDP.

Grubler, A. (2002). Trends in global emissions: Carbon, sulfur, and nitrogen. In T. Munn (Ed.), Encyclopedia of global environmental change. Chichester: John Wiley \& Sons.

Grübler, A., Nakicenovic, N., Alcamo, J., Davis, G., Fenhann, J., Hare, B., et al. (2004). Emissions scenarios: A final response. Energy \& Environment, 15(1), 11-24.

Halsnæs, K., Kühl, J., \& Olesen, J. (2007). Turning climate change information into economic and health impacts. Climatic Change, 81(0), 145-162.

Holdren, J. P., \& Smith, K. R. (2000). Energy, the environment and health. In J. Goldemberg (Ed.). World energy assessment, energy and the challenge of sustainability. New York: UNDP.

Hosier, R. H., \& Dowd, J. (1987). Household fuel choice in Zimbabwe: An empirical test of the energy ladder hypothesis. Resources and Energy, 9(4), 347-361.

IEA (2002). World energy outlook 2002. Paris: International Energy Agency.

IMAGE-team (2001). The IMAGE 2.2 implementation of the IPCC SRES scenarios. A comprehensive analysis of emissions, climate change and impacts in the 21 st century (No. RIVM CD-ROM publication 481508018). Bilthoven, the Netherlands: National Institute for Public Health and the Environment.

IPCC (2000a). Special report on emission scenarios. Cambridge: Intergovernmental Panel on Climate Change, Cambridge University Press.

IPCC (2000b). SRES final data. Ciesin: <http: sres.ciesin.org >. Retrieved May 23, 2005.

Jung, T. Y., La Rovere, E. L., Gaj, H., Shukla, P. R., \& Zhou, D. (2000). Structural changes in developing countries and their implication for energy-related $\mathrm{CO}_{2}$ emissions. Technological Forecasting and Social Change, 63(2-3), 111-136.

Kahn, M. E., \& Pfaff, A. S. P. (2000). Informal economies, information and the environment. Journal of International Affairs, 53(2), 525-544. 
Kainuma, M., Matsuoka, Y., \& Morita, T. (Eds.) Climate policy assessment, Asia-Pacific integrated modeling. Tokyo: Springer-Verlag.

Kander, A. (2002). Economic growth, energy consumption and $\mathrm{CO}_{2}$ emissions in Sweden 1800-2000. Stockholm Almqvist \& Wiksell International.

Kander, A. (2005). Baumol's disease and dematerialization of the economy. Ecological Economics, 55(1), 119-130.

Kituyi, E., Marufu, L., Huber, B., Wandiga, S. O., Jumba, I. O., Andreae, M. O., et al. (2001). Biofuel consumption rates and patterns in Kenya. Biomass and Bioenergy, 20(2), 83-99.

Kooijman, A. (2005). Energy choices in SME's in rural areas. Paper presented at the UNDP expert meeting on Productive Uses of Renewable Energy.

Kuznets, S. (1955). Economic growth and income inequality. The American Economic Review, 45(1), $1-28$.

Lafrance, R., \& Schembri, L. (2002). Purchasing power parity: Definition, measurement and interpretation. Bank of Canada Review, Autumn 2002.

Lindmark, M. (2004). Patterns of historical $\mathrm{CO}_{2}$ intensity transitions among high and low-income countries. Explorations in Economic History, 41(4), 426-447.

Lucon, O., Painuly, J. P., Fifita, S., Arvizu, D. E., Tsuchiya, H., \& Wohlgemuth, N. (2006). Is renewable energy cost-effective?. Natural Resources Forum, 30(3), 238-240.

Martins, J. (2005). The impact of the use of energy sources on the quality of life of poor communities. Social Indicators Research, 72(3), 373-402.

Masera, O. R., Saatkamp, B. D., \& Kammen, D. M. (2000). From linear fuel switching to multiple cooking strategies: A critique and alternative to the energy ladder model. World Development, 28(12), 2083-2103.

Mori, S. (2000). The development of greenhouse gas emissions scenarios using an extension of the MARIA model for the assessment of resource and energy technologies. Technological Forecasting and Social Change, 63(2-3), 289-311.

Mosley, S. (2001). The chimney of the world: A history of smoke pollution in Victorian and Edwardian Manchester. Isle of Harris: The White Horse Press.

Mulugetta, Y., Nhete, T., \& Jackson, T. (2000). Photovoltaics in Zimbabwe: Lessons from the GEF solar project. Energy Policy, 28(14), 1069-1080.

Nakicenovic, N., Grubler, A., \& McDonald, A. (Eds.) (1998). Global energy perspectives. Cambridge, UK: Cambridge University Press.

Nordhaus, W. (2007). Alternative measures of output in global economic-environmental models: Purchasing power parity or market exchange rates? Energy Economics, 29(3), 349-372.

O'Brien, K., Leichenko, R., Kelkar, U., Venema, H., Aandahl, G., Tompkins, H., et al. (2004). Mapping vulnerability to multiple stressors: Climate change and globalization in India. Global Environmental Change Part A, 14(4), 303-313.

OECD/NEA (1985). The economics of the nuclear fuel cycle. Paris: OECD/NEA.
Pandey, R. (2002). Energy policy modelling: Agenda for developing countries. Energy Policy, 30(2), 97-106.

Quadrelli, R., \& Peterson, S. (2007). The energy-climate challenge: Recent trends in $\mathrm{CO} 2$ emissions from fuel combustion. Energy Policy, 35(11), 5938-5952.

Raupach, M. R., Marland, G., Ciais, P., Le Quere, C., Canadell, J. G., Klepper, G., et al. (2007). Global and regional drivers of accelerating $\mathrm{CO}_{2}$ emissions. Proceedings of the National Academy of Sciences, 104(24), 10288-10293.

Reddy, A. K. N. (2000). Energy and social issues. In J. Goldemberg (Ed.). World energy assessment, energy and the challange of sustainability. New York: UNDP.

Reddy, A. K. N., \& Goldemberg, J. (1990). Energy for the developing world. Scientific American, 263(3), 111.

Rogner, H.-H. (1997). An assessment of world hydrocarbon resources. Annual Review of Energy and the Environment, 22(1), 217-262.

Saith, A. (1983). Development and distribution: A critique of the cross-country U-hypothesis. Journal of Development Economics, 13(3), 367-382.

Schneider, F. (2005). Shadow economies around the world: What do we really know? European Journal of Political Economy, 21(3), 598-642.

Schneider, F. (2006). Personal communication. Johannes Kepler University of Linz, Austria.

Schneider, F., \& Enste, D. H. (2000). Shadow economies: Size, causes and consequenses. Journal of Economic Literature, 38(1), 77-114.

Shukla, P. R. (1995). Greenhouse gas models and abatement costs for developing nations: A critical assessment. Energy Policy, 23(8), 677-687.

Smith, K. R., Apte, M. G., Yuqing, M., Wongsekiarttirat, W., \& Kulkarni, A. (1994). Air pollution and the energy ladder in asian cities. Energy, 19(5), 587-600.

Smith, S. J., Pitcher, H., \& Wigley, T. (2005). Future sulfur dioxide emissions. Climatic Change, 73(3).

Srivastava, L., \& Misra, N. (2007). Promoting regional energy co-operation in South Asia. Energy Policy, 35(6), 3360-3368.

Stern, D. I. (2004). The rise and fall of the environmental kuznets curve. World Development, 32(8), 1419-1439.

Storchmann, K. (2005). Long-run gasoline demand for passenger cars: The role of income distribution. Energy Economics, 27(1), 25-58.

Top, N., Mizoue, N., Kai, S., \& Nakao, T. (2004). Variation in woodfuel consumption patterns in response to forest availability in Kampong Thom Province, Cambodia. Biomass and Bioenergy, 27(1), 57-68.

Urban, F., Benders, R. M. J., \& Moll, H. C. (2007). Modelling energy systems for developing countries. Energy Policy, 35(6), 3473-3482.

van der Sluijs, J. P., Potting, J., Risbey, J., van Vuuren, D., de Vries, B., Beusen, A., et al. (2001). Uncertainty assessment of the IMAGE-TIMER B1 $\mathrm{CO}_{2}$ emissions scenario, using the NUSAP method (No. 410200104 (2002)). Dutch National Research Program on Climate Change. 
van Vuuren, D. P., \& Alfsen, K. (2006). PPP versus MER: Searching for answers in a multi-dimensional debate. Climatic Change, 75(1), 47-57.

van Vuuren, D. P., Cofala, J., Eerens, H. E., Oostenrijk, R., Heyes, C., Klimont, Z., et al. (2006). Exploring the ancillary benefits of the Kyoto Protocol for air pollution in Europe. Energy Policy, 34(4), 444-460.

van Vuuren, D. P., den Elzen, M., Lucas, P., Eickhout, B., Strengers, B., van Ruijven, B., et al. (2007). Stabilizing greenhouse gas concentrations at low levels: An assessment of reduction strategies and costs. Climatic Change, 81(2), 119-159.

van Vuuren, D. P., Strengers, B. J., \& De Vries, H. J. M. (1999). Long-term perspectives on world metal use- a system-dynamics model. Resources Policy, 25(4), 239-255.

Victor, N. M., \& Victor, D. G. (2002). Macro patterns in the use of traditional biomass fuels (Working paper). Stanford: Stanford University.

WHO (2006). Indoor air pollution and health. <http:// www.who.int/mediacentre/factsheets/fs292/en/index.html>. Retrieved April 4, 2006.

World Bank (2004). World development indicators (CDROM).

Xiaohua, W., \& Zhenmin, F. (2005). Study on affecting factors and standard of rural household energy consumption in China. Renewable and Sustainable Energy Reviews, 9(1), 101-110.

Available online at www.sciencedirect.com 